\title{
Stereoselective Synthesis of Densely Substituted Tetrahydroquinolines by a Conjugate Addition nitro-Mannich Reaction with Carbon Nucleophiles
}

\author{
James C. Anderson* \\ Christopher D. Rundell \\ Department of Chemistry, University College London, 20 \\ Gordon Street, London WC1H OAJ, UK. \\ j.c.anderson@ucl.ac.uk
}

Dedicated to my friend and mentor Professor Steven $\mathrm{V}$

Ley for his guidance and inspiration.

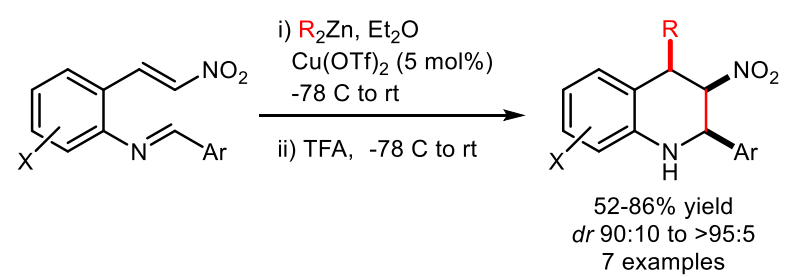

aniline imine gives highly versatile and stereodefined nitrosubstituted tetrahydroquinolines. We devised a diastereoselective intramolecular nitro-Mannich route to trans3-nitrotetrahydroquinolines $\mathbf{3}$ (Scheme 1), ${ }^{7}$ which has recently been shown by Maity and Pan to be enantioselective through the use of a bifunctional tertiary amine thiourea catalyst. ${ }^{8} \mathrm{~A}$ tandem conjugate addition nitro-Mannich sequence has also been shown to give cis, trans-nitrotetrahydroquinolines $4 .{ }^{9}$<smiles>[X]c1ccccc1/C=C/C(=O)O[Na]</smiles>

Scheme 1 Relevant reported work.

Following on from our work defining stereoselective nitroMannich reactions initiated by conjugate addition to nitroalkenes, ${ }^{10}$ we reasoned that conjugate addition of a nucleophile to an imino-nitrostyrene could trigger an intramolecular nitro-Mannich reaction to form contiguous stereocentres (Scheme 2). We first exemplified this strategy with the cyclisation of 2-imino-nitrostyrenes triggered by a conjugate hydride addition and subsequent intramolecular nitro-Mannich reaction to give the corresponding cis-2-aryl-3nitrotetrahydroquinolines as single diastereoisomers, in high yields and enantioselectivities. ${ }^{11}$ In this work we wish to report the extension of this methodology to the use of carbon nucleophiles in the conjugate addition step to give stereodefined cis, cis-2,3,4-trisubstituted tetrahydroquinolines. 


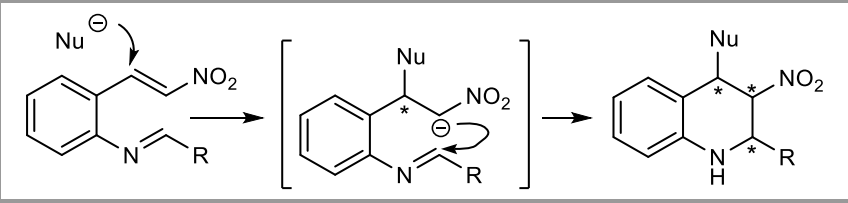

Scheme 2 Proposed reaction.

We had already developed an expedient synthesis of sensitive 2imino-nitrostyrenes $\mathbf{5}$ through the radical nitration of the corresponding 2-imino-styrenes. ${ }^{11}$ Cyclisation of $\mathbf{5 a}$ was investigated using the conditions ${ }^{12}$ we had used previously while developing the enantioselective copper catalysed dialkylzinc conjugate addition nitro-Mannich reaction. ${ }^{10 a}$ Treatment of $\mathbf{5 a}$ with diethyl zinc ( 1.5 equiv.) in the presence of catalytic $\mathrm{Cu}(\mathrm{OTf})_{2}$ ( $5 \mathrm{~mol} \%$ ) in $\mathrm{Et}_{2} \mathrm{O}$ at $-78{ }^{\circ} \mathrm{C}$ with warming to rt led to complete conjugate addition in up to 120 mins, as judged by thin layer chromatography. Recooling of the reaction mixture to $-78{ }^{\circ} \mathrm{C}$, addition of trifluoroacetic acid and warming to room temperature to complete the nitro Mannich reaction, gave a $62 \%$ isolated yield of the 2,3,4-trisubstituted tetrahydroquinoline $\mathbf{6 a}$, essentially as a single diastereoisomer by ${ }^{1} \mathrm{H}$ NMR (Figure 2). ${ }^{13}$ We have observed that the dialkylzinc conjugate addition nitroMannich reaction does not usually tolerate ortho-subsituents. ${ }^{10 a, g}$ The success of this reaction may imply binding of the copper organometallic reagent to the imine lone pair and assisting the reaction in some way. The sense of diastereoselectivity was determined by inspection of $3 \mathrm{~J}$ coupling constants between the vicinal protons adjacent to the $\mathrm{C}-2$ phenyl ring and the $\mathrm{C}-3$ nitro function. The signal assigned to $\mathrm{C}-2 \mathrm{H}(\delta 4.76,1 \mathrm{H}, \mathrm{d}, J=3.3 \mathrm{~Hz})$ was directly coupled to the $\mathrm{C}-3 \mathrm{H}(\delta 4.98,1 \mathrm{H}, \mathrm{t}, J=2.9 \mathrm{~Hz})$. The coupling constant between $\mathrm{C}-2 \mathrm{H}$ and $\mathrm{C}-3 \mathrm{H}$ is in the range ${ }^{3} J_{\text {cis }} \sim 3-4 \mathrm{~Hz}$ which is what we determined for a series of cis-2-aryl-3nitrotetrahydroquinolines ${ }^{11}$ and is clearly smaller than the equivalent trans-2-aryl-3-nitrotetrahydroquinolines coupling constant ${ }^{3} J_{\text {trans }} \sim 8 \mathrm{~Hz}^{7}$ Proton $\mathrm{C}-3 \mathrm{H}$ is also coupled to $\mathrm{C}$ $4 \mathrm{H}(\delta 3.20,1 \mathrm{H}, \mathrm{ddd}, J=8.3,5.3,2.4 \mathrm{~Hz})$ with ${ }^{3} \mathrm{~J}=2.4 \mathrm{~Hz}$, indicative again of a cis- relationship between the $\mathrm{C}-3$ nitro function and the C-4 ethyl substituent. This leads to the cis, cis- relative stereochemistry assigned to $\mathbf{6} \mathbf{a}$.

A plausible transition state model can be drawn building on our previous models ${ }^{7}$ and those of others (Figure 3).8,9 Our reaction must proceed by conjugate addition first to give nitronate species 7. Upon addition of acid the transition state leading to the kinetic cis-nitro-Mannich product can be represented by $\mathbf{8}$ in which the intramolecular hydrogen bond between the putative iminium ion proton and the nitronate group provides stabilisation through a Zimmerman Traxler like transitiisiton state. The alkyl stereocentre from the conjugate addition can adopt an equatorial conformation to avoid a destabilising pseudo-axial interaction with the proton $\mathrm{H}_{\mathrm{a}}$. However, the resulting cis, cisstereochemistry of $\mathbf{6}$ is in contrast to the stereochemistry reported by Jia for their proposed conjugate addition nitroMannich reaction product cis, trans-4 (Scheme 1), the relative stereochemistry of which was confirmed by single crystal X-ray diffraction. ${ }^{9}$ These workers suggested a similar transition state model to 8 but required their $-\mathrm{CH}_{2} \mathrm{CO}$.Ph substituent to occupy the energetically unfavourable pseudoaxial position. It would seem more likely, from a stereochemical point of view, that product $\mathbf{4}$ is formed from a nitro-Mannich conjugate addition reaction sequence where the enone group can occupy a favourable equatorial disposition in the final cyclisation step.

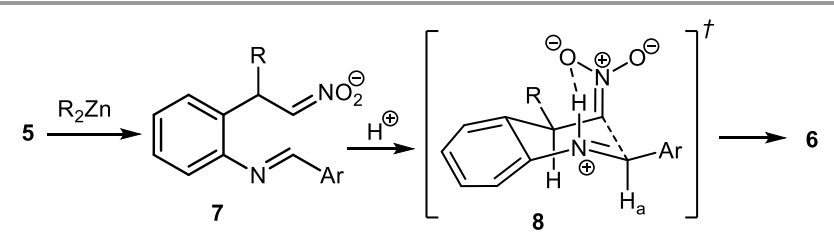

Figure 3 Suggested transition state model to account for sense of diastereoselection

The generality of the procedure for the synthesis of other cis, cis2,3,4-trisubstituted tetrahydroquinolines 6 was investigated (Figure 2). All products were prepared in good yield and high diastereoselectivity as judged by ${ }^{1} \mathrm{H}$ NMR. The sense of diastereoselectivity was identical as each compound exhibited similar ${ }^{3} \mathrm{~J}$ coupling constants between $\mathrm{C}-2 \mathrm{H}, \mathrm{C}-3 \mathrm{H}$ and $\mathrm{C}-4 \mathrm{H}$. The isolated compounds were stable, but in solution were prone to elimination of $\mathrm{HNO}_{2}$ and oxidation to the quinolienes over a period of days. No discernible link between the slight variation in yields and diastereoselectivities with the electronic or steric character of the imine substituent could be made. However when $\mathrm{Ar}=p-\mathrm{NO}_{2} \mathrm{C}_{6} \mathrm{H}_{5}$, although the ${ }^{1} \mathrm{H}$ NMR of the crude reaction mixture showed complete consumption of starting material to the conjugate addition product and $\sim 40 \%$ cyclised product, neither of them could be isolated after column chromatography on silica. As we have noted before, the poor conversion in this case is most probably due to the electron withdrawingn imine function not participating in the nitro-Mannich reaction due to the lower reactivity of the imine lone pair, the protonation of which is required for the nitro-Mannich reaction to proceed. ${ }^{15}$ In addition certain nitro-Mannich products are susceptible to retroaddition and cannot be easily purified.10a,b,d The use of dimethylzinc gave $\mathbf{6 g}$ with good diastereoselectivity in a slightly lower yield ith the samethan with substrate (5a) and diethylzinc. ${ }^{16}$ 


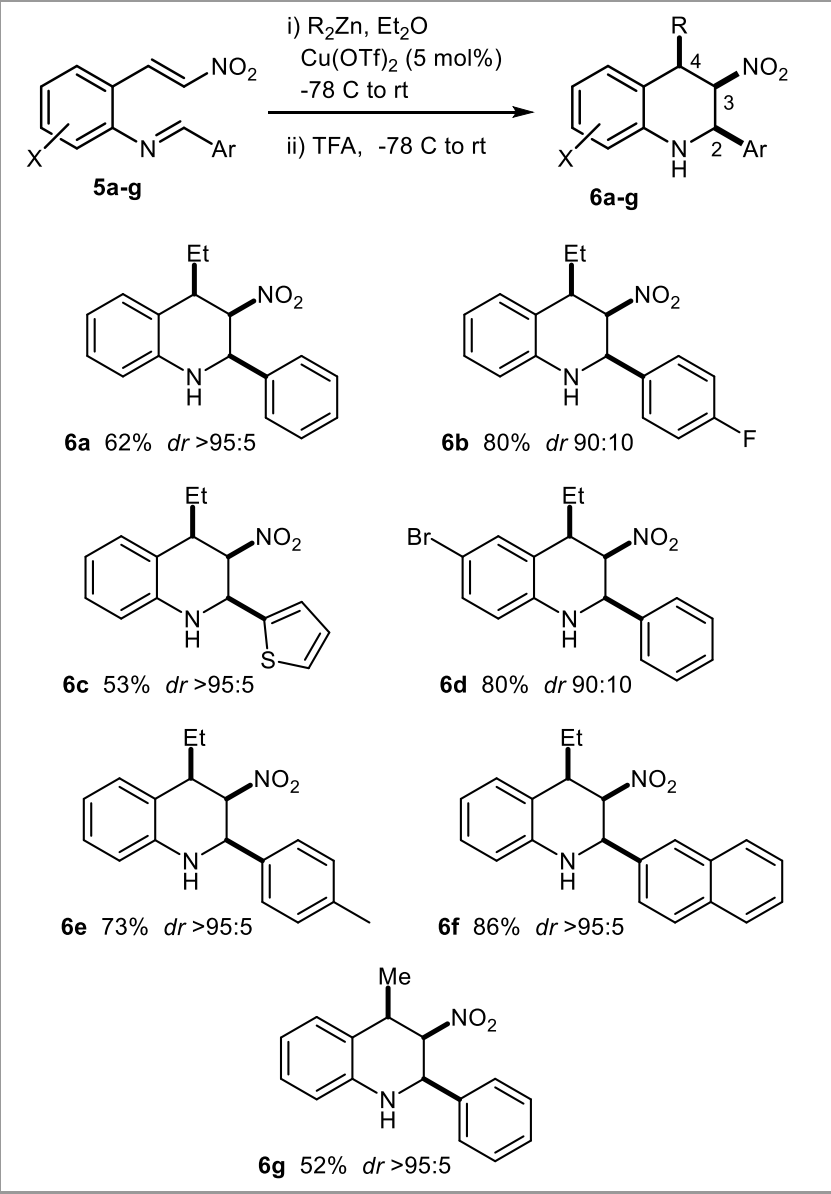

Figure 2 Copper catalysed dialkylzinc conjugate addition intramolecular nitroMannich reaction. ${ }^{14}$ Yields refer to isolated and purified yields. Diastereomeric ratios were identical in the crude ${ }^{1} \mathrm{H}$ NMR and purified materials.

In summary we have developed a highly diastereoselective synthesis of cis, cis-2,3,4-tetrahydroquinolines through the copper catalysed dialkylzinc conjugate addition nitro-Mannich reaction. The stereodefined products 6 incorporate a stereogenic nitro function which is a versatile synthetic handle that can be transformed into amines, carbonyl groups or be denitrated. ${ }^{17} \mathrm{We}$ have preliminarily investigated the control of absolute stereochemistry in this reaction by conducting the copper catalysed conjugate addition in the presence of known chiral ligands optimised for nitrostyrenes.10a,c These have given virtually racemic results. This could be due to internal complexation by the imine lone pair disrupting chiral ligand binding (vide supra) and as noted by Ojima et al.,18 the ligand systems are affected by steric bulk at the ortho-position, lowering enantioselectivites. Other methods to initiate this cyclisation by asymmetric conjugate addition are being investigated and will be reported in due course. These products should serve as useful chiral building blocks for further functionalisation towards biologically active targets.

\section{Acknowledgment}

We thank the Engineering and Physical Sciences Research Council (DTA), University College London (UCL) and AstraZeneca for funding, Dr. K. Karu (UCL) for mass spectra and Mrs. J. Maxwell (UCL) for microanalytical data.

\section{Supporting Information}

YES (Detailed experimental procedures and characterization data)

\section{Primary Data}

NO (this text will be deleted prior to publication)

\section{References and Notes}

(1) For reviews, see: (a) Nammalwar, B.; Bunce, R.A. Molecules 2014, 19, 204. (b) Sridharan, V.; Suryavanshi, P. A.; Menéndez, J. C. Chem. Rev. 2011, 111, 7157. (c) Zhou, Y.-G. Acc. Chem. Res. 2007, 40, 1357. (d) Mitchinson, A.; Nadin, A. J. Chem. Soc. Perkin Trans. 12000 , 2862. (e) Kouznetsov, V.; Palma, A.; Ewert, C.; Varlamov, A. J. Heterocycl. Chem. 1998, 35, 761. (f) Katrizky, A. R.; Rachwal, S.; Rachwal, B. Tetrahedron 1996, 52, 15031.

(2) Asolkar, R.N.; Schroeder, D.; Heckmann, R.; Lang, S.; WagnerDoebler, I.; Laatsch, H. J. Antibiot. 2004, 57, 17.

(3) Ransom, R. W.; Graham, A. C.; Bernard, A. M.; Salvatore, M. J.; Lumma, W. C.; Anderson, P. S.; Pitzenberger, S. M.; Varga, S. L. J. Am. Chem. Soc. 1995, 117, 6682.

(4) For examples, (a) Ueda, M.; Kawai, S.; Hayashi, M.; Naito, T.; Miyata, O. J. Org. Chem. 2010, 75, 914. (b) Tan, H. R.; Ng, H. F.; Chang, J.; Wang, J. Chem. Eur. J. 2012, 18, 3865. (c) Jia, Z.-X.; Luo, Y.-C.; Wang, Y.; Chen, L.; Xu, P.-F.; Wang, B. Chem. Eur. J. 2012, 18, 12958. (d) Wang, K.-T.; Kim, S.-G. Synthesis 2014, 3365.

(5) For examples, (a) Youn, S. W.; Song, J.-H.; Jung, D.-I. J. Org. Chem. 2008, 73, 5658. (b) Davies, S. G.; Mujtaba, N.; Roberts, P. M.; Smith, A. D.; Thomson, J. E. Org. Lett. 2009, 11, 1959. (c) Kang, Y. K.; Kim, S. M.; Kim, D. Y. J. Am. Chem. Soc. 2010, 132, 11847. (d) Suh, C. W. Kim, D. Y. Org. Lett. 2014, 16, 5374. (e) Cao, W.; Liu, X.; Guo, J.; Liu, L.; Feng, X. Chem. Eur. J. 2015, 21, 1632.

(6) Noble, A.; Anderson, J. C. Chem. Rev., 2013, 113, 2887.

(7) Anderson, J. C.; Noble, A.; Ribelles Torres, P. Tetrahedron Lett. 2012, 53, 5707.

(8) Maity, R.; Pan, S. C. Org. Biomol. Chem. 2015, 13, 6825.

(9) Jia, Z.-X.; Luo, Y.-C.; Xu, P.-F. Org. Lett. 2011, 13, 832.

(10) (a) Anderson, J. C.; Stepney, G. J.; Mills, M. R.; Horsfall, L. R.; Blake, A. J.; Lewis, W. J. Org. Chem. 2011, 76, 1961. (b) Anderson, J. C.; Blake, A. J.; Koovits, P. J.; Stepney, G. J. J. Org. Chem. 2012, 77, 4711. (c) Anderson, J. C.; Horsfall, L. R.; Kalogirou, A. S.; Mills, M. R.; Stepney, G. J.; Tizzard, G. J. J. Org. Chem. 2012, 77, 6186. (d) Anderson, J. C.; Noble, A.; Tocher, D. A. J. Org. Chem. 2012, 77, 6703. (e) Anderson, J. C.; Koovits, P. J. Chem. Sci. 2013, 4, 2897. (f) Anderson, J.C.; Kalogirou, A.S; Tizzard, G.J. Tetrahedron 2014, 17, 9337. (g) Anderson, J. C.; Campbell, I. B.; Campos, S.; Shannon, J.; Tocher, D. A. Org. Biomol. Chem. 2015, 13, 170.

(11) Anderson, J.C.; Barham, J.P.; Rundell, C.D. Org. Lett. 2015, 17, 4090.

(12) Alexakis, A.; Vastra, J.; Mangeney, P. Tetrahedron Lett. 1997, 38, 7745.

(13) The crude ${ }^{1} \mathrm{H}$ NMR also showed $>95: 5$ diastereoselectivity.

(14) A solution of 5 (0.25 mmol) and $\mathrm{Cu}(\mathrm{OTf})_{2}(5 \mathrm{~mol} \%)$ in $\mathrm{Et}_{2} \mathrm{O}$ (2.5 $\mathrm{mL}$ ) was cooled to $-78{ }^{\circ} \mathrm{C}$ over 30 minutes. A solution of $\mathrm{ZnEt}_{2}$ ( $0.375 \mathrm{~mL}$ of a $1.0 \mathrm{M}$ solution in Hexanes, 1.5 equiv.) was added and the mixture stirred for up to 1 hour and then stirred for up to 2 hours at room temperature. The resulting suspension was recooled to $-78{ }^{\circ} \mathrm{C}$ over 30 minutes and TFA ( 2.5 equiv.) was added drop wise, stirred for up to 1 hour and then stirred for up to 1 hour at room temperature. The reaction was then quenched with saturated aqueous $\mathrm{NaHCO}_{3}(50 \mathrm{~mL})$, extracted with EtOAc or DCM $(3 \times 30 \mathrm{~mL})$, the combined organic layers washed with brine $(100$ $\mathrm{mL})$, dried $\left(\mathrm{Na}_{2} \mathrm{SO}_{4}\right)$ and concentrated in vacuo to give the crude tetrahydroquinoline 6 . Purification by column chromatography gave the pure tetrahydroquinoline 6. Data for 6a (44 mg, 62\%); $\mathrm{R}_{\mathrm{f}}$ $=0.33$ (1:1 DCM:Hexanes); IR $v_{\max }$ (neat) $3416(\mathrm{~N}-\mathrm{H}), 1545(\mathrm{~N}-\mathrm{O})$, $1368(\mathrm{~N}-0) \mathrm{cm}^{-1} ;{ }^{1} \mathrm{H} \mathrm{NMR}\left(\mathrm{CDCl}_{3}, 500 \mathrm{MHz}\right) \delta 7.32-7.45(\mathrm{~m}, 5 \mathrm{H}$, $\operatorname{ArH})$, 7.08-7.16 (m, 2H, ArH), $6.82(\mathrm{t}, J=7.5 \mathrm{~Hz}, 1 \mathrm{H}, \mathrm{ArH}), 6.68(\mathrm{dd}$, $J=7.9,1.3 \mathrm{~Hz}, 1 \mathrm{H}, \mathrm{Ar} H$ ), 4.98 (app. t, $J=2.9 \mathrm{~Hz}, 1 \mathrm{H}, \mathrm{CHNO}_{2}$ ), 4.76 (d, $J=3.3 \mathrm{~Hz}, 1 \mathrm{H}, \mathrm{CHPh}$ ), $4.25(\mathrm{~s}, 1 \mathrm{H}, \mathrm{N} H), 3.20$ (ddd, $J=8.3,5.3,2.4 \mathrm{~Hz}$, $1 \mathrm{H}, \mathrm{CHEt}), 1.69-2.01\left(\mathrm{~m}, 2 \mathrm{H}, \mathrm{CH}_{2} \mathrm{CH}_{3}\right), 1.12(\mathrm{t}, J=7.4 \mathrm{~Hz}, 3 \mathrm{H}$, $\left.\mathrm{CH}_{2} \mathrm{CH}_{3}\right) ;{ }^{13} \mathrm{C} \mathrm{NMR}\left(\mathrm{CDCl}_{3}, 151 \mathrm{MHz}\right) \delta 142.5(\mathrm{ArC}) .138 .1(\mathrm{ArC})$, 129.4 (ArCH), $129.1(\mathrm{ArCH}), 129.1(\mathrm{ArC}), 127.6(\mathrm{ArCH}), 126.8$ 
$(\mathrm{ArCH}), 121.2(\mathrm{ArCH}), 118.8(\mathrm{ArCH}), 114.7(\mathrm{ArCH}), 86.8(\mathrm{CH}), 54.6$ $(\mathrm{CH}), 41.8$ (CHEt), $30.7\left(\mathrm{CH}_{2} \mathrm{CH}_{3}\right), 11.6\left(\mathrm{CH}_{2} \mathrm{CH}_{3}\right) ; \mathrm{m} / \mathrm{z}$ (ESI) 234 $\left(100 \%, \quad \mathrm{M}^{-} \mathrm{H}_{3} \mathrm{NO}_{2}+\right),\left(45 \%, \mathrm{M}+\mathrm{H}^{+}\right) ; \quad \mathrm{HRMS} \quad \mathrm{C}_{17} \mathrm{H}_{19} \mathrm{~N}_{2} \mathrm{O}_{2}$ calcd. 283.1447, found 283.1448 .

(15) Adams, H.; Anderson, J.C.; Peace, S.; Pennell, A.M.K. J. Org. Chem. 1998, 63, 9932.
(16) Use of $\mathrm{AlMe}_{3}$ gave no reaction.

(17) Ono, N. The Nitro Group in Organic Synthesis; Wiley-VCH: New York, 2001.

(18) Choi, H.; Hua, Z.; Ojima, I. Org. Lett. 2004, 6, 2689 